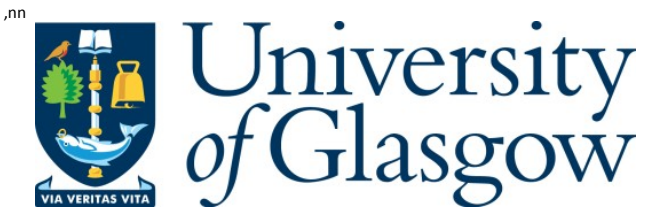

M enter, I., and Hulme, M . (2009) Teacher researchers in the UK: what are their needs? Some lessons from Scotland. In: Campbell, $A$. andG roundwater-Smith, $S$. (eds.) Connecting Inquiry and Professional Learning in Education: International Perspectives and Practical Solutions. Routledge: London, pp. 109-121. ISBN 9780415478120

Copyright @ 2009 Routledge

A copy can be downloaded for personal non-commercial research or study, without prior permission or charge

Content must not be changed in any way or reproduced in any format or medium without the formal permission of the copyright holder(s)

$\underline{\text { http://eprints.gla.ac.uk/41114/ }}$

Deposited on: 09 A pril 2015

Enlighten - Research publications by members of the U niversity of Glasgow http://eprints.gla.ac.uk 


\section{Teacher researchers in the UK: what are their needs? Some lessons from Scotland}

Ian Menter and Moira Hulme

\section{Introduction}

This chapter critically reflects on the needs of teacher researchers at different career stages in Scotland: beginning teachers, early career teachers (0-5 years) and experienced colleagues. It draws on a current research project to illustrate some of the dilemmas and tensions for teacher researchers and their supporters or mentors in this shared enterprise. Research to Support Schools of Ambition (2006-2009)[1] is a collaborative project funded by the Scottish Government wherein university-based mentors support teacher researchers in a network of fifty-two secondary schools (pupils aged 11-16/18 years) distributed throughout Scotland (Menter and Hulme, 2007).

The resurgence of interest in teacher research over the last decade offers possibilities for the development of new relationships between the policy, practitioner and research communities. Collaborative enquiry has been associated with the promotion of collegial practices in schools, the democratising of research relations and the encouragement of participatory decision making in schools (through devolved leadership) (Stenhouse, 1975; Carr and Kemmis, 1986; Elliot, 1991, 2004; Noffke, 1997; Kincheloe, 1991; Cochran-Smith and Lytle, 1993, 1999). Proponents of educational action research have long argued that traditional 'outsider' research contributes to the disenfranchisement of teachers; and that the exclusion of practitioners from debates about the professional knowledge base of teaching leaves the profession vulnerable to external intervention (McNamara, 1993). Practitioner research is frequently aligned with a commitment to move from 'communities of practice' towards 'professional learning communities' (Street and Temperley, 2005; McLaughlin et al, 2006). Renewed interest in teacher research accompanies moves towards integrated professional development frameworks within the United Kingdom, across Europe and elsewhere (Jephcote et al, 2007). A great deal of attention is currently focused on teachers' professional development amidst moves to standardise and harmonise qualification frameworks internationally (NfER, 2006). The move towards Masters level postgraduate programmes in the UK further extends opportunities to enhance research engagement at an early stage in teacher formation (DCSF, 2008).

These opportunities, however, proceed within a context of increased central regulation of teacher education and teachers' work (Furlong, 2005; Mahony and Hextall, 2000; Olssen et al, 2004). There are a number of paradoxes in the promotion of teacher research that require further consideration, especially teacher research programmes that are sponsored by government agencies, sometimes in partnership with business sponsors or philanthropic foundations[2]. Within higher education, public responses to the endorsement of particular forms of sponsored teacher-led enquiry, on a national scale, have tended to be under-theorised. From a policy sociology perspective it is necessary to consider the broader context within which programmes to promote cultures of self-evaluation and systematic self-study within schools are located. At a time when practitioner enquiry is being actively promoted across the career phases, we consider the contextual constraints on school-based enquiry and make a contribution towards problematising the role of higher education in supporting teachers as researchers. In particular we draw attention to the need for reflexivity in considering partnership work with schools. The promotion of practicebased research requires partners to consider 'technical' issues of means but also ethical and 
political issues regarding the parameters, purposes and ends of enquiry. Of significance here is the degree of self-determination achieved in the selection of research 'problems' - the difference between problem solving and problem posing practices (Campbell, 2003).

In this chapter we critically examine teacher learning and development in the context of the Schools of Ambition work. While there is no doubt that this project has had a significant impact on the professional identities of a number of teachers across Scotland, it is also the case that there have been major constraints on the achievement of the full potential for learning, as was originally aspired to. The conclusion to the chapter sets out some suggestions about the conditions that might be required for a fuller realization of teacher empowerment through research activity and engagement.

\section{The policy context}

In Scotland, research engagement is embedded within the professional development framework for teachers in Scotland (Kirkwood and Christie, 2006). There is an expectation that, from an early stage in professional formation, Scottish teachers will use 'research and other forms of valid evidence to inform choice, change and priorities in promoting educational practices and progress' (GTC/QAA, 2006:4). The Standard for Initial Teacher Education (SITE)[3] expects that, by the end of a programme of initial teacher education, beginning teachers will 'know how to access and apply relevant findings from educational research' and 'know how to engage appropriately in the systematic investigation of practice' (GTCS/QAA, 2006:11). The Standard for Full Registration (SFR) expects registered teachers to have 'research-based knowledge relating to learning and teaching and a critical appreciation of the contribution of research to education in general' (GTCS, 2006:11). A commitment to 'critical self-evaluation and development' is one of the core professional values and personal commitments within the Standard for Chartered Teacher (GTCS, 2002:1). The Chartered Teacher[4] is required to demonstrate a capacity to 'evaluate practice and reflect critically on it' and to 'ensure that teaching is based on reading and research' (GTCS, 2002:10). The Scottish teacher is thus not positioned as 'policy cipher' or 'compliant implementer of curriculum designs and pedagogies' that have developed elsewhere; further evidence of this Scottish distinctiveness appears in the model of teacher preparation advanced in the Scottish Teachers for a New Era programme[5] (Livingston and Colucci-Gray, 2006).

\section{Participation in teacher research}

When teachers participate in research as an elective activity there is the potential for research engagement to open up new spaces for teachers to assert their agency. The following section draws on thirty-four interviews with some of the teacher researchers who are leading strands of evaluation activity within the Scottish Schools of Ambition (June and July 2007). These included a range of promoted and non-promoted teachers. The interviews focused on a number of core themes: participants' previous engagement with 'research', how they became involved in schoolbased enquiry, the support that was available to them, difficulties encountered, processes that supported sharing and collaboration in and beyond the school and the contribution of research 
engagement to individuals' professional development.

The teachers' accounts revealed different routes into participation according to individuals' position in the career structure. The 2001 Agreement, A Teaching Profession for the $21^{\text {st }}$ Century, sought to address the 'hierarchical nature of teacher culture in Scotland' (MacDonald, 2004:414) by simplifying and flattening the career structure to afford greater opportunities for non-promoted teachers. Many authorities have moved towards 'faculty' structures in secondary schools, wherein Principal Teachers have management and curriculum responsibility for clusters of subjects rather than a single subject department. These faculty leaders are positioned as 'learning leaders', leading local developments in curriculum and pedagogy. It is, as yet, unclear whether the reduction in the ratio of promoted posts has produced 'a more collegiate profession' (MacBride, 2007, column 3957). The involvement of many non-promoted teachers in evaluation activities was through a process of targeted recruitment rather than responding to open invitations to participate from senior management or other colleagues in school. More senior colleagues were undertaking research because it 'was part of their remit', aligned with their day-to-day responsibilities. The method of recruitment influenced teachers' attitudes to enquiry. The allocation of 'projects' to people was a source of discomfort for some teachers, who nonetheless valued the opportunity to participate and hoped to develop their 'own' research in the future. The concentration of research activity in this way created a perception of personal ownership. Research is reduced to an individual responsibility to be packaged in CPD portfolios and appraised at review meetings, rather than as a 'stance' or commitment to sustainable whole school change (Cochran-Smith and Lytle, 2001).

'The most important thing for me would be being able to choose what the focus of my research was within the school improvement plan. Teachers are professionals. We're all intelligent people. We can make our own decisions and we can read the school improvement plan and decide on an area.' Classteacher

'I was selected. I didn't put forth that I was interested in action research. I was chosen because I had career aspirations and I think that this school said, 'well here's a project to run with. See if you can build up your profile'. Classteacher

'I wish it had been put out to staff to say what are you interested in? Do you wish to do any sort of research? So you could have chosen your own; so you had a burning desire. It would be much easier to do the action research if you genuinely had a real issue with it.' Classteacher

The way in which teachers responded to becoming involved in school enquiry depended on their interpretation of the purpose of the research activity - the perceived benefits for themselves and for the school - and their confidence in carrying research plans forward. Many of the teacher researchers expressed initial uncertainty about how to proceed and what was expected of them. Participation in small-scale evaluation studies, based on an action enquiry model, was regarded as challenging. Some teachers, especially those whose previous 'research' experience was informed by a 'scientific' paradigm, were initially unsettled and uncomfortable with an alternative investigative approach. Equally whilst all participants were experienced in producing data for routine performance monitoring, several doubted whether they possessed the necessary skills to interpret statistical data for evaluation purposes. In the early stages there was a tendency to seek 
cause and effect relations and an expectation that investigations would suggest ready solutions to complex problems of practice. In this way, in some accounts, enquiry was translated into a form of 'answerism' (Goodson, 2003). In all cases there was external pressure to evidence impact derived from the additional resource provided through School of Ambition status.

Initial low levels of confidence were evidenced in requests for 'exemplars' of evaluation planning sheets by teachers leading specific strands of enquiry. There was a strong desire to conform to an over-arching generic model, rather than ground investigations within a specific set of local circumstances; although responsiveness to local needs was a key feature of each school's 'transformational plan'. The busyness of life in school created a pull towards compliance with an assumed 'preferred' model of enquiry (context free) rather than more open forms of questioning that started from a particular context (situated). The role of the mentor was important in promoting a range of ways of thinking about the evaluation process and in considering a range of sources of evidence, especially qualitative indicators or 'soft' measures. This was particularly important in formulating responses to the need for schools to gather baseline measures of pupil self-esteem, confidence and aspirations.

Accommodating extended roles and responsibilities within existing workloads is a key challenge in the promotion of teacher research, even within schools where there is a strong commitment to such developments (as discussed by Hulme, 2008). In taking on the interrelated roles of teacher and researcher/evaluator, time was cited as the main barrier to making progress by all participants irrespective of position on the management structure, recruitment route and motivation. In most cases teachers struggled to maintain negotiated schedules of planned activities.

'Do I do the project or do I develop a new thing for my higher class[6]? I'm here to teach and of course my priorities will always go with that, so it's finding time to sit down and get things started.' Classteacher

'It is a lot of extra work and you start to feel burdened by it. I have to keep reminding myself - and it's helped me to cope with stress better, I think - no, I can't do that and I shouldn't be expected to do that. This research is here to support what I am doing, not to make what I am doing more burdensome, you know.' Classteacher

University-based mentors' sought to encourage a scholarly and critical engagement with existing literature, but many of the teachers expressed considerable difficulty in identifying relevant sources of research evidence that were accessible to a practitioner audience. The teachers could not access a wide range of electronic resources (databases and electronic journals) without registering with the university library and none of the schools opted to do this. In addition to time and ready access, a restricted level of information literacy was in some cases a limiting factor. Teachers who endeavoured to engage with the literature often lacked confidence in discriminating between sources and were unsure about the criteria in making choices from the wealth or dearth of material that their searches generated. The negative experience of trying to engage with available literature strengthened a perception of doing research as extra work, an 'add-on', detached from the core concerns of a classteacher. Paradoxically, for some teachers, the involvement of the university mentors was associated with a loss of control over the activity, which the mentors were seeking to strengthen through critical engagement with wider literature. This encouragement was 
interpreted by some teachers as an unrealistic demand on their time and as peripheral to their main motivation in becoming involved.

\section{Meeting the needs of teacher researchers}

The promotion of practitioner research from the late 1990s opened up new opportunities for tutors in higher education to become involved in supporting school-led research. The sponsorship of applied and practice-based research can be read from a number of perspectives within the academy (Furlong and Oancea, 2006, 2007). For some this represented an incursion into areas which were previously the preserve of higher education and 'professional' researchers. Advocates of evidence-informed practice saw possibilities to bring greater rigour to decision making in schools (Hargreaves, 1996; Hopkins, 2001, MacBeath, 1999). For others renewed interest in teachers as researchers offered possibilities to address the 'disenfranchisement' of teachers (McNamara, 2002, Saunders, 2004).

Political legitimation was afforded to teacher research as a means of strengthening the link between theory and practice and tackling the 'two communities' problem. MacLure (1996:274), among others, has written of the well rehearsed 'oppositional dilemmas' between 'theory and practice; between the personal and the professional; between the organisational cultures of schools and the academy; between 'insider' and 'outsider' perspectives; between the sacred languages of science, scholarship or research, and the mundane dialects of practice and everyday experience' (see also Sikes and Potts, 2008). Teacher researchers are not usually writing for publication nor are they necessarily participating on award bearing courses. They are essentially concerned with the task of 'doing the job better'.

School-based enquiry is primarily concerned with achieving improvements for pupils, rather than contributing to public codified knowledge. Teacher researchers' interests are typically tied to a specific local context, rather than aspiring to wider generalisable claims. Oral/visual presentations at face-to-face workshops and networking events are favoured as appropriate strategies for sharing good practice in schools, rather than formal academic writing. Research 'quality' is likely to be assessed in terms of relevance and credibility in the context of practice by schools, before judgements of 'theoretical and methodological robustness' (Furlong and Oancea, 2006). For many teacher researchers the process of undertaking the enquiry is as important as the findings. Teachers focus not on the contribution of research to the production of new knowledge, but the generation of practice-relevant knowledge. Whilst wary of asserting essentialist or unitary readings of 'the' teacher and 'the' university researcher, the cultural values of the school emphasise the 'practicality ethic' of teaching (Doyle and Ponder, 1977). Teacher researchers are more likely to be concerned with producing outcomes that are 'immediate, relevant and actionable' (Ebbutt et al., 2000:329). The creation of a practitioner-centered model of collaborative enquiry does not remove these differences and potential tensions, which remain resilient to the solutions of 'policy magic' (Ball, 1998:124) such as those conjured in Hargreaves' (1999) conception of the 'knowledge creating school'.

Selecting teacher educators as research mentors is appropriate for a number of reasons. Mentoring is central to the task of supporting beginning teachers and to the promotion of continuing professional learning among experienced teachers. University departments with established 
traditions of collaborative working within ITE and CPD networks are well placed to support practitioner research and have a relatively secure basis on which to claim a shared language and shared culture with practitioners in schools. The requirement of 'recent and relevant experience' and the involvement of seconded 'teacher tutors' strengthens these claims. Mentors selected from within ITE are 'boundary crossers', having made the transition from enquiring teacher to teacherresearcher to teacher educator, though the changes undertaken in 'leaving teaching' and assuming a new identity in higher education should not be underestimated (MacLure, 1996; Murray, 2005; Murray and Male, 2005).

However critics have also suggested that the position of teacher educators in relation to both schools and universities can create difficulties as well as drivers to partnership work. It has been argued that the degree of familiarity and extent of acculturation may lead some within teacher education to seek to protect the traditional craft culture of schools. Strong bonds within 'communities' are not necessarily positive and there is an emerging body of work on the deleterious consequences of negative social capital[7].

A key tension in supporting beginning teacher researchers is the issue of the application of quality standards within a public framework of accountability. Differing views on the nature of educational research and the place and quality of teacher research create dilemmas for mentors who position themselves outside the funder's frame of reference. In reconciling competing demands to both support and challenge teachers as they undertake evaluation activities, mentors are guided by an ethical commitment towards an 'ethos of care' when working with others (Zeni, 2001). In practice, the dilemma faced between the exertion of 'academic authority' and a commitment to support teachers finding their way in a demanding set of circumstances, can result in a loosening of levels of engagement. Difficulties in satisfactorily reconciling competing positions may invoke detachment: disengagement or distancing from the requirement to make a judgement that might be deemed 'harmful' (or at least discouraging) to participants. A subtle shifting of position away from quality assurer or evaluator towards the role of supporter or counsellor changes the nature of the relationship between mentor and mentee.

In standing back from confronting mentees with fundamental quality judgements, the mentor's position may slip along the reflectivity-activity continuum resulting in mentors adopting a more pragmatic approach to their role. Here greater attention is afforded to manageability (making it happen) rather than questions around the educational ends that might be served by the process. This sense making is associated with assessing the impact of specific interventions and bringing a research focus to the routine data gathering that takes place in schools. Support for teachers becomes the provision of practical guidance in terms of action planning and target setting. The mentor's role is reduced to one of timekeeper and task manager, organising a timeline for activities and supervising completion of interim stages of activity. The core task is essentially one of helping busy teachers to keep their investigation in their sights and to focus on the next steps. She emphasises practical (and important) issues of manageability, feasibility, scale. This is a practical, task-oriented view of collaboration that is essentially concerned with 'doing' the investigation - supporting the teacher as much as the enquiry; providing solutions rather than posing questions. Whilst necessary when helping novice researchers with full-time teaching commitments to manage heavy workloads, this is a shallow model of collaboration that does not include more critically reflective consideration of (shared) aims and values. The relationship that 
could be achieved in these complex circumstances is one of 'bounded collaboration....which does not reach deep down to the grounds, the principles or the ethics of practice' (Hargreaves, 1992:228). The extent to which 'ownership' of the research process remains with the teacher in this directional model is questionable. The focus here is on the teacher's responsibility in completing the work. The teacher's choices are made in the context of setting targets to support the progression of the evaluation. A key element of the mentor's role is the encouragement of selfregulation within the given parameters of the project plan; in the case of Schools of Ambition, a plan devised by school management and ratified by Senior Advisors from the Scottish Government.

The value of the practical support offered by the mentors cannot be underestimated as teachers struggled to juggle commitments and find time for their investigations. Several teachers spoke of the difficulties involved in sharing work-in-progress in a fragmented and congested school day. Difficulties in communicating plans and in coordinating activities across the school were repeatedly expressed. Whilst there was evidence of a willingness to engage with others in the research, this proved challenging at both an organisational and interpersonal level. It is likely that the restricted opportunities for dialogue that were available to teachers prevented the generation of new ideas and challenges that would have supported further learning. In relation to Little's (1990) four types of collegiality - story telling, help, sharing and joint work - as indicators of collegial interaction, there was little evidence that activity in the schools progressed towards the forms of mutual interdependence associated with 'joint work'. Most communication about the research among the teacher researchers was conducted 'informally' at the level of sharing stories and seeking help. A culture of 'privacy' (Nias et al, 1989) and the enduring realities of teacher isolation and subject-based territoriality are well documented barriers to greater sharing and collaborative enquiry in secondary schools (Cochran-Smith and Lytle, 1993). Teachers talked about the difficulty of engaging the interest of colleagues and questioned the wider relevance of their work beyond their own classrooms and curricular responsibilities. This hesitancy contributed to processes of responsibilisation; as individual owners of separate projects they each needed to see the activity through to its 'private completion'.

\section{Conclusion}

In this chapter we have argued that school-university research partnerships need to be placed within a specific context. Participants bring their personal past experiences to new initiatives, including that of their initial teacher education, which are similarly influenced by the prevailing cultural and structural context and by previous histories of partnership work. In interrogating the notion of partnership it is necessary to consider the communities that such work endeavours to bridge. The concepts of community and partnership carry positive connotations as descriptors of 'positive social conditions' (King, 2002:245). Whilst one might question the tendency to overstate the internal cohesion of each 'community', there are very significant and well documented differences between the organisational cultures of schools and university departments of education - although of course the latter have also been subject to major incursions of managerialism over the past twenty to thirty years. These differences are embedded within the political project of centrally sponsored and coordinated practice-based research and are worked through by participants as they engage with and make sense of their respective roles and assumed place within this shared work. 
Significant tensions were experienced in the early stages of research engagement within the Schools of Ambition by all participants. These included a web of personal, practical, professional and ethical dilemmas. Rather than the ideal of 'comfortable collaboration and critical reflection' described by Peters (2002:240), our experience suggests that mentors working with schools are likely to experience periods of uncomfortable collaboration, notably characterised by a conflicting interest between supporting and challenging mentees. It is hardly surprising given the considerable workloads of teachers that they value hints and tips rather than reflective prompts and are exasperated and dispirited if this kind of support is not forthcoming from mentors they position as 'experts'. This is consistent with Smedley's (2001:196) claim that for many teacher researchers " "know how' is more important than 'knowing that' or 'knowing why". A preference for toolkits and recipe knowledge may align with the broader movement in teacher education towards the 'teacher as technician' (Zeichner and Liston, 1996) - mastering the techniques of delivery rather than engaging in questions of educational purpose and value. The model of learning through mentoring that many of the teachers aspire towards is closer to Alexander's (1990) notion of 'imitation' than a sense of 'exploration' based on curiosity. Resistance or difficulties encountered in negotiating the literature maze meant that many accounts fell back to 'describing' developments, giving an 'account of' rather than 'accounting for' preferred ways of working. This is not to deny that considerable professional learning has occurred for many of the teachers involved; rather it is to say that much of this has been more limited than might originally have been hoped.

This chapter has proceeded from the position that an understanding of teacher research needs to be located within an understanding of teaching as 'work' (Ozga, 1988; Nias, 1989) and accordingly affords attention to the discourses that currently frame teaching and re-articulated versions of 'teacher research'. Studies of teachers as researchers have tended to focus on the products of enquiry, rather than the context in which such enquiries are made possible and enacted (Furlong and Salisbury, 2005). On the one hand, expressions of the 'new localism' in the self-managing school and the commitment within the 'new professionalism' to a 'career of learning' can be seen to suggest processes of empowerment. Devolution of responsibility has the potential to enhance the professional status of teachers and increase the local autonomy of school leaders. One of the main arguments advanced for extending opportunities for practitioner research is the potential it offers for 'professional growth' (Somekh and Saunders, 2007). Initial experiences within the Schools of Ambition, however, have identified tensions between the aspirations of 'extended' or 'democratic professionalism' (Sachs, 2003) and contemporary culture and performance management in secondary schools.

In examining the role of school-university research partnerships in supporting school-based professional learning, it is important to consider the nature of 'evidence' and the purposes of evidence collection and analysis in schools; as well as the shifting relations of authority, license and control between schools, universities and central government. Devolution of responsibility necessarily involves accounting procedures: the production of a quantifiable evidence base to demonstrate effectiveness at an individual and institutional level. Deliberation on the criteria for self-evaluation continues to work on the school from the outside-in. These powerful constraining influences on experienced teachers cut across and undermine the commitment to critical enquiry engendered in the early stages of professional formation, which in Scotland includes the development of a highly regarded programme of teacher induction (Draper and O'Brien, 2006). 
Although the rhetoric of the self-managing school and the teacher-as-researcher are seductive, devolving responsibilities to schools does not necessarily produce more 'democratic' or 'expansive' forms of professionalism. As Smyth (1993:1) notes, 'educational systems are about acquiring more power, not giving it away' (original emphasis). The orientation of 'fast policy' towards 'fast solutions' to the 'problems' of practice, reinforces rather than challenges the 'discourse of delivery' in schools (Fielding, 2003; McIntyre, 2005). From this perspective the language of 'what works' represents a form of 'answerism' and 'political quietism' (Goodson, 2003). Teacher research within sponsored programmes can become a form of 'managed empowerment' that is technique and outcomes-focused. This chapter has sought to problematise the professionalising claims of teacher research in order to better support teachers as they engage in professional enquiry in their schools. The potential for teacher research to enhance the standing of the profession depends on teachers' capacity to respond creatively within the structures and cultures in which they work. The outcome of this endeavour will depend, in part, on the relations of partnership that are negotiated with higher education. In order for such partnerships to be fully productive they are likely to grow from collaboration in the early stages of teacher preparation, through induction and early professional development and into career-long further development. Our account of the Scottish experience, where there is greater evidence of the policy context being facilitative of this kind of approach demonstrates what a major challenge this is. How much greater may it be where the constraining effects of the twin pressures of performativity and accountability are even greater?

\section{References}

Alexander, R. (1990). Partnership in initial teacher education: confronting the issues. In M. Booth \& J. Furlong \& M. Wilkin (Eds.), Partnership in Teacher Education (pp. 59-73). London: Cassell.

Ball, S. J. (1998). Big Policies/Small World: an introduction to international perspectives in education policy. Comparative Education, 34(2), 119-130.

Campbell, A. (2003). Teachers; Research and Professional Development in England: some questions, issues and concerns. Journal of In-Service Education, 29(3), 375-388.

Carr, W. and Kemmis, S. (1986) Becoming Critical: Education, Knowledge and Action Research. Lewes, Falmer.

Christie, D. (2003) Competences, Benchmarks and Standards in Teaching in Bryce, T. and Humes, W. (eds.) Scottish Education Second Edition., post-devolution), (pp 952-63). Edinburgh: University Press.

Cochran-Smith, M., \& Lytle, S. L. (1993). Inside Out: Teacher Research and Knowledge. New York: Teachers College.

Cochran-Smith, M., \& Lytle, S. L. (1999). The teacher research movement: a decade later. Educational Researcher, 28(7), 15-25.

Cochran-Smith, M., \& Lytle, S. L. (2001). Beyond Certainty: Taking an Inquiry Stance on Practice. In A. Lieberman \& L. Miller (Eds.), Teachers Caught in the Action: Professional Development that Matters (pp. 45-60). New York: Teachers' College Press.

Cochran-Smith, M. (2006). Taking stock in 2006: evidence, evidence everywhere. Journal of Teacher Education, 57, 6-12.

DCSF (2008) Being the Best for Our Children: Releasing talent for teaching and learning, 


\section{London: DCSF}

Doyle, W., \& Ponder, G. A. (1977). The Practicality Ethic in Teacher Decision Making. Interchange, 8(3), 1-12.

Draper, J. and O'Brien, J. (2006) Induction: fostering career development at all stages, Edinburgh: Dunedin Academic Press.

Ebbutt, D., Robson, R., \& Worrall, N. (2000). Educational Research Partnership: differences and tensions at the interface between the professional cultures of practitioners in schools and researchers in higher education. Teacher Development, 4(3), 319-337.

Fielding, M. (2003). The impact of impact. Cambridge Journal of Education, 33(2), 289-295.

Furlong, J. (2005). New Labour and teacher education: the end of an era. Oxford Review of Education, 31(1), 119-134.

Furlong, J., \& Oancea, A. (2006). Assessing Quality in Applied and Practice-Based Research in Education: a framework for discussion. Review of Australian Research in Education: Counterpoints on the Quality and Impact of Educational Research. Australian Educational Researcher, 6(Special Issue), 89-104.

Furlong, J., \& Salisbury, J. (2005). Best Practice Research Scholarships: an evaluation. Research Papers in Education, 20(1), 45-83.

Goodson, I. F. (2003). Professional Knowledge, Professional Lives: Studies in education and change. Maidenhead: Open University Press.

GTCS/QAA (2006) The Standard for Initial Teacher Education. Edinburgh, GTCS.

GTCS. (2002). Standard for Full Registration. Edinburgh: GCTS.

Hargreaves, A. (1992). Cultures of teaching: A focus for change. In A. Hargreaves \& M. Fullan (Eds.), Understanding Teacher Development (pp. 216 - 236). New York: Teachers College Press.

Hargreaves, D. (1996). Teaching as a research-based profession: Possibilities and prospects. Paper presented at the Teacher Training Agency Annual Lecture, University of Cambridge, Department of Education.

Hargreaves, D. (1999). The Knowledge Creating School. British Journal of Educational Studies, $47(2), 122-144$.

Hopkins, D. (2001). School Improvement for Real. London: Routledge.

Hulme, M. (2008) Researching teachers, changing teachers: practitioner research and the modernisation of teaching. Unpublished $\mathrm{PhD}$, Keele University.

King, M. B. (2002). Professional development to promote schoolwide inquiry. Teaching and Teacher Education, 18, 243-257.

Kirk, G., Beveridge, W. and Smith, I. (2003) The Chartered Teacher, Edinburgh: Dunedin Academic Press.

Kirkwood, M., \& Christie, D. (2006). The role of teacher research in continuing professional development. British Journal of Educational Studies, 54(4), 429-448.

Little, J.W. (1990) The persistence of privacy: Autonomy and initiative in teachers' professional relations. Teachers College Record, 91:509-536.

Livingston, K. and Colucci-Gray, L. (2006) Scottish Teachers for a New Era: where should we start from, if not together? Education in the North, 14, 36-37.

Macbeath, J. (1999). Schools Must Speak for Themselves: The Case for School Self-Evaluation. London: Routledge.

MacBride (2007) Education Committee, Official Report. 24 January 2007, column 3957.

Mahony, P., \& Hextall, I. (2000). Reconstructing Teaching: Standards, Performance and Accountability. London: Routledge/Falmer. 
McDonald, A. (2004). Collegiate or compliant? Primary teachers in post-McCrone Scotland. British Educational Research Journal, 30, 413-433.

MacLure, M. (1996) Telling Transitions: boundary work in narratives of becoming an action researcher. British Educational Research Journal, 22(3),273-286.

McGonigal, J., Hulme, M. and McDonald, A. (2007) Teachers' Lives and Work: Social Capital, Professional Knowledge and Teacher Formation. Online paper completed for the Applied Educational Research Scheme (AERS) Schools and Social Capital Network http://www.aers.org.uk/access/content/group/ssc/AUG\%20Inter\%20trans\%20report\%20to\% 20PMcG-1_1_.doc [electronic source: 09.01.2007]

McIntyre, D. (2005). Bridging the gap between research and practice. Cambridge Journal of Education, 35(3), 357-382.

McLaughlin, C., Black-Hawkins, K., Brindley, S., McIntyre, D., \& Taber, K. S. (2006). Researching Schools: Stories from a Schools-University Partnership for Educational Research. London: Routledge.

McNamara (1993) McNamara, O. (Ed.). (2002). Becoming an Evidence-Based Practitioner: a framework for teacher researchers. London: Routledge.

Menter, I. and Hulme, M. (2007) Research to support Schools of Ambition, Education in the North, 15, 47-50.

Murray, J. (2005). Re-addressing the priorities: new teacher educators and induction in higher education. European Journal of Teacher Education, 28(1), 67-85.

Murray, J., \& Male, T. (2005). Becoming a teacher educator: evidence from the field. Teaching and Teacher Education, 21(2), 125-142.

National Foundation for Educational Research (2006) Cross Nation Research into Mutual Qualifications. Belfast, NfER.

Nias, J. (1989). Primary Teachers Talking: A Study of Teaching as Work. London: Routledge.

Nias, J., Southworth, G., \& Yeoman, R. (1989). Staff Relations in the Primary School: A Study of Organisational Cultures. London: Cassell.

Noffke, S. E. (1997). Professional, personal and political dimensions of action research. Review of Research in Education, 22, 305-343.

Ozga, J. (Ed.). (1988). Schoolwork: Approaches to the Labour Process of Teaching. Milton Keynes, Open University Press.

Quality Assurance Agency for Higher Education. (2000). The Standard for Initial Teacher Education in Scotland. Gloucester, QAA.

Sachs, J. (2003). The Activist Teaching Profession. Buckingham: Open University Press.

Saunders, L. (2004, 14 March). Grounding the Democratic Imagination: Developing the Relationship between Research and Policy in Education. Professorial lecture. London: University of London, Institute of Education.

Scottish Executive (2001) A Teaching Profession for the $21^{\text {st }}$ Century (McCrone Agreement), Edinburgh: Scottish Executive.

Sikes, P., \& Potts, A. (Eds.). (2008). Researching Education from the Inside: Investigations from within. London: Routledge.

Smedley, L. (2001). Impediments to partnership: a literature review of school-university links. Teachers and Teaching: Theory and Practice, 7(2), 189-209.

Smyth, J. (Ed) (1993) A Socially Critical View of the Self-Managing School. London: Falmer.

Somekh, B., \& Saunders, L. (2007). Developing knowledge through intervention: meaning and definition of 'quality' in research into change. Research Papers in Education, 22(2), 183197. 
Street, H., \& Temperley, J. (2005). Improving Schools through Collaborative Enquiry. London: Continuum.

Zeichner, K., \& Liston, D. (1996). Reflective Teaching: An Introduction: Lawrence Erlbaum.

Zeni, J. (Ed.). (2001). Ethical Issues in Practitioner Research. New York: Teachers College Press.

[1] This project is being carried out with colleagues at the University of Glasgow (Viv Baumfield, Alison Devlin, Beth Dickson, Dely Elliot, Stuart Hall, Kay Livingston and Kevin Lowden), the University of Aberdeen (Norman Coutts, Fran Payne, Dean Robson and Jenny Spratt) and the University of Strathclyde (Donald Christie, Sanna Rimplilainen).

[2] For example, the Hunter Foundation in Scotland, <http://www.thehunterfoundation.co.uk/>

[3] The twenty-four elements that comprise the Standard for Initial Teacher Education (SITE) (QAA, 2000) (revised 2006) were generated by a benchmarking group that contained representatives from each of the Teacher Education Institutions (TEIs), the General Teaching Council, a primary headteacher, a secondary headteacher, a representative from the local authorities, a member of the schools' inspectorate (HMIE) and an observer from the Quality Assurance Agency for Higher Education (QAA) (Christie, 2003).

[4] The Chartered Teacher (CT) Programme was introduced in August 2003 and is open to all teachers who have reached the top of the main grade teachers' pay scale and who have maintained a CPD portfolio. Progression through the CT grade is by qualification i.e. progression through a self-funded twelve module Master's degree. Course members can claim up to $50 \%$ of the programme by Accreditation of Prior Learning (APL). There is also an accelerated route through submission of a folio to General Teaching Council for Scotland. See Kirk et al, 2003, for more details.

[5] The design of the project is based on the USA scheme, Teachers for a New Era, which is largely funded by the Carnegie Corporation. There the approach is described as adopting a clinical practice approach to teacher education. Whilst there is some concern among observers in Scotland with the 'instructional' conception of the teacher's role in this programme, there is felt to be merit in its attention to evidenceinformed continuous review of practice, with 'evidence' being broadly defined to include professional/user perspectives; or 'evidence plus' (Cochran Smith, 2006:11).

[6] Reference to 'higher class' indicates a group that is taking the Higher Certificate, a public examination for senior pupils in Scotland.

[7] As illustrated in the work of the Applied Educational Research Scheme (AERS) five year programme 'Schools and Social Capital', funded by The Scottish Government and the Scottish Funding Council (McGonigal, Hulme and MacDonald, 2007). 